\title{
TYPOLOGY OF DYSGRAPHIA ERRORS IN PERFORMING THE WRITING TASK 'PRODUCING YOUR OWN TEXT' BY BILINGUAL PRIMARY-SCHOOL STUDENTS
}

\author{
Gencho Valchev ${ }^{1}$, Diyana Georgieva ${ }^{2}$
}

\begin{abstract}
The article presents the results of a field logopedic study of third- and fourth-grade bilingual students and the research material created by them while carrying out a writing task of producing a text of their own. The aim of the experiment is to analyze the quantitative and qualitative parameters of the dysgraphia errors in bilingual students (ethnic Roma and Turks) at the text level and on this basis to identify their typology and dependence on some linguistic and social factors. For the purposes of the research, a toolkit has been developed that includes groups of methods for the study of the following: the psychosomatic and the academic status, the elementary graphic habits; the phonemic gnosis; writing in different situations; identification and typologization of typographical errors through a criterion system. The results clearly show that the prevailing errors made by the bilinguals are analytic-synthetic. Regarding the other types of errors, significant differences have not been registered. The analysis of the results showed significant differences in terms of gender, ethnicity/language status and type of settlement.
\end{abstract}

UDC Classification: 376, DOI: https://doi.org/10.12955/pss.v1.82

Keywords: typographical errors, bilingualism, written text, factors.

\section{Introduction}

The language development of the child is an integral part of its social development and one of the components of its socialization as a person. Socialization, in turn, is a process of mastering a complex of social roles. Each role corresponds to certain norms of social and linguistic behavior, depending on the situation and conditions of communication. The process begins in kindergarten and continues in primary school, where children learn not only the correct speech, but also the peculiarities of written communication. The problems of children from ethno-cultural and ethno-linguistic minorities are already evident in kindergarten, they deepen and become more complicated in primary school. These problems are related not so much to the influence of ethno-cultural and socio-cultural factors, as to the linguistic peculiarities of the environment in which the children live. The linguistic situation in which the children of bilinguals (Turks and Romas) are raised and brought up is different depending on the degree of mastery of the Bulgarian language as a second language. As a science that takes as its subject matter language and speech disorders, as well as their rehabilitation and prevention, speech therapy has a special status in the study of bilingualism and in solving the problems related to the education, upbringing and socialization of bilinguals.

\section{Literature Review}

The concepts discussed in the field of theoretical interpretations of bilingualism point to the finding that there are no significant differences in the definition of the phenomenon of bilingualism. Many authors' research reflects a wide range of issues related to the education, literacy and social adaptation of bilingual children (Simeonova, 2007; Stamov, 1989; Kyuchukov, 2002; Weekes, 2005; Sebastian et al. 2011; Houghton \& Zorzi, 2003; Koleva, 1994). Researchers agree on the notion that bilingualism is a linguistic phenomenon with a socio-psychological basis and is not associated with neuropsychological and general somatic pathogenesis in these children. Bilingualism is a psychic mechanism (knowledge, skills and habits) that allows a linguistic person to move freely from one language to another, depending on the linguistic situation. There are also differences in the positions of individual authors, but they are manifested in the definition of the types of bilingualism and are by no means contradictory to each other. Rather, they are a consequence of the definition aspect - the criteria by which the types of bilingualism are grouped and differentiated.

The coexistence of two languages in an individual is a complex phenomenon. The bilinguals' use of language, as pointed out by Wei (2002), involves such factors as degree (the proficiency level of the language that an individual has), function (for what an individual uses his languages, the roles his languages played in his total pattern of behavior), alternation (the extent to which one alternates between one's languages, how one changes from one language to another, and under what conditions) and interference (how well the bilingual keeps his languages apart, the extent to which he fuses them, how one of his languages influences the use of another). Particular difficulties in mastering a second language

\footnotetext{
${ }^{1}$ Trakia University, Faculty of Education, Stara Zagora, Bulgaria, gval@abv.bg

2 Trakia University, Faculty of Education, Stara Zagora, Bulgaria, paskaldi1929@abv.bg
} 
and achieving complete bilingualism are created by the phenomenon of interference, which is by consensus defined as a change in the structure or the elements of one linguistic system under the influence of another. According to the researchers, interference is widespread at all levels of the language sign system in second language acquisition (Kyuchukov, 2002; Rowse \& Wilshire, 2007). The penetration of phonetic, grammatical and lexical elements of the mother tongue into the second language (the one being studied) is initially at the level of oral expression, since oral speech is formed in the process of natural development. Written communication is the result of specialized training. Written speech is a form of verbal speech through graphically represented language means. Here, sounds are replaced by graphic linguistic characters. The foundation of writing is language and speech as a universal medium of communication. The analysis of the literary sources on the problems of mastery of writing and interference in children bilinguals shows that, as a whole, it has a negative impact on the acquisition of the second language, both at the level of oral and written production (Chen et al. 2010; Abu-Rabia \& Siegel, 2002). At the same time all studies provide support to Cummins' "threshold hypothesis" which holds that "a threshold level of linguistic competence must be attained both in order to avoid cognitive disadvantages and allow the potentially beneficial aspects of bilingualism to influence his cognitive and academic functioning" (Cummins, 1976, p. 3). Figueredo (2006) carried out a review of 27 studies examining the development of spelling ability in bilingual children. The review supported the notion that positive or negative transfer will take place depending on individual language characteristics. Positive transfer will occur when commonalities exist among orthographies (such as common letters) or strategies used, e.g., phonological or visual skills. On the other hand, negative transfer will occur when, due to lack of competent L2 awareness, rules specific to first language (L1) are generalized to second this one. In the studies examined in the review, eight found positive transfer and three found negative transfer effects, and one study did not find any cross-linguistic effects.

In the course of the study of the literary sources, the conceptual conclusions about the empirical statements and the solutions to the research problem were formed: Firstly, in the process of active interaction with the child's social and physical environment, cognitive processes develop, sustainable communication and social-behavioral models are mastered. Secondly, the psychological and pedagogical analysis of the development of children bilinguals shows serious difficulties in their inclusion in social microstructures and in the acquisition of the necessary educational content. Thirdly, language interference in children bilinguals influences the overall verbal communication - both oral and written. As written speech has more stringent requirements in its implementation, it takes more time and is more difficult to master. Therefore, the risk of experiencing difficulties in the process of its acquisition is higher. The bilingual child requires longer and more focused efforts to learn a particular volume of vocabulary, as well as to learn the stylisitc and grammar rules of the respective language and adhere to them in written practice. As a result, a conflict is generated between the requirements of the comprehensive school, on the one hand, and the objective capabilities of the child, on the other. Difficulties arise in the literacy mastering and the acquisition of written communication competences.

The main aim of this study is to analyze the quantitative and qualitative parameters of the dysgraphia errors in bilingual students (ethnic Roma and Turks) at the text level and on this basis to identify their typology and dependence on some linguistic and social factors.

\section{Data and Methodology}

The null hypotheses presented correspond to the main purpose of the research and the conceptual conclusions from the analysis of the scientific literature. They are:

- $\mathbf{H}_{\mathbf{0}}$ 1: There is no significant difference between the number of analytical-synthetic spelling errors (ASDE) - a consequence of the influence of language interference, and the other two types of dysgraphia errors (VSCPL, WL) made in the written text by students in the formed groups (monolinguals and bilinguals).

- $\mathbf{H}_{0}$ 2: There is no significant difference between the number of types of dysgraphia errors observed in students speaking Bulgarian verbal language (monolinguals) and students (Romas and Turks) using other linguistic codes in communication and Bulgarian language.

- $\mathbf{H}_{0}$ 3: There is no significant difference between the number of types of dysgraphia errors recorded in the boys and in the girls participating in the experiment.

- $\mathbf{H}_{\mathbf{0}}$ 4: There is no significant difference between the number of types of dysgraphia errors registered in the students living in different demographic areas: big city, small town, village. 
The experiment has the character of a field logopedic study. The subject area defines the research field. The object of the study is the written communication of third- and fourth-grade bilingual students (of Turkish and Roma ethnic origin). The subject of the study is the typology of the dysgraphia errors made by the students in performing the written task of "producing their own text". The linguistic task is accomplished through a written retelling of a text whose content and volume are tailored to the students' age and curriculum.

In accordance with the research aim purposive sampling was used. The sample was formed from students from the third and fourth grades of primary schools in different localities in Bulgaria. 548 students from 27 classes of 10 general education schools in six populated areas were covereded. The latter are divided according to their types: type I - big city, type II - small town, type III - village. Two large research groups are identified: bilinguals (Romas and Turks) and monolinguals (Bulgarians), which represent the control group. The groups are differentiated on the basis of certain criteria: ethnicity, gender, type of settlement. The total number of Roma bilingual students is 161 (73 girls and 88 boys), the ethnic Turks are 146 ( 70 girls and 76 boys) and the Bulgarians are 241 (138 girls and 103 boys). A typical feature of the settlements covered is that they are home to compact masses of bilinguals (of Roma and Turkish ethnic origin). Outside of the Bulgarian general education school, they only communicate in the language (dialect) of their ethnic community. The control group consists of students of Bulgarian ethnic origin (monolinguals), of the same classes in the described settlements. They speak the Bulgarian language. The experimental study consists of verbal stimuli in Bulgarian. Linguistic test covers all levels of the hierarchical structure of the language sign system. The verbal material (texts) is in accordance with the age and cognitive characteristics of the students.

The identification and typologization of the dyscgraphia errors was performed according to the following classification criteria: Spatial-co-ordination-spelling errors (VSCPL); Misspellings errors (WL); Analytical-synthetic spelling errors (ASDE).

The evaluation of the results is carried out according to the quantitative and qualitative criteria of the diagnostic procedure.

The statistical procedure is performed by formulating the necessary statistical hypotheses. The obtained research data were subjected to processing and statistical analysis using a built-in function ANOVA: Single Factor Microsoft Office 2010.

\section{Results}

The analysis of the spelling errors was performed on the basis of the completed language task to retell in a written form a text through presenting the stimulus twice. The analysis was conducted in two directions: the distribution of the errors by type and the distribution of students who made dysgrphia errors according to ethnicity, gender, and type of settlement.

When examining the results of this designed study four separate hypothesis were tested. The first null hypothesis suggested that the number of ASDE (a consequence of the influence of language interference) manifested by the monolinguals and bilinguals would not be significantly different from other two types of dysgraphia errors (VSCPL, WL) made in the written text. The next three null hypotheses proffered that the number and quality of dysgraphia errors demonstrated by observed students would not be significantly different depending on their ethnicity, gender, and the type of settlement they inhabited.

The differences are statistically significant when $\mathbf{F}>\mathbf{F}$ crit and the alternative hypothesis is accepted.

The first null hypothesis aimed to determine the difference between the total number of analyticalsynthetic spelling errors (ASDE) and the other two types of dysgraphia errors (VSCPL, WL) made in the written text by students in the formed groups. Review of the data indicated the predominance of the analytical-synthetic spelling errors over the errors related to space-coordinate letter placement and misspellings errors (Table1). The values of the check value confirm the statistical significance of the observed difference $(\mathrm{F}=3.982298, \mathrm{~F}$ crit=1.42667). The obtained results give a reason for rejecting the null hypothesis and accepting the alternative hypothesis. 


\begin{tabular}{|l} 
Table 1: One-way analysis of variance for the relationship between the types of disgraphia errors \\
\hline \begin{tabular}{|l|c|c|c|c|c|}
\hline $\begin{array}{l}\text { Source of } \\
\text { Variation }\end{array}$ & SS & df & MS & F & F crit \\
\hline $\begin{array}{l}\text { Between } \\
\text { Groups }\end{array}$ & 36406.38 & 2 & 18203.19 & 3.982298 & 1.42667 \\
\hline $\begin{array}{l}\text { Within } \\
\text { Groups }\end{array}$ & 1400351.3 & 11 & 12759.21 & & \\
\hline & & & & & \\
\hline Total & 176757.7 & 13 & & & \\
\hline
\end{tabular} \\
Source: Authors
\end{tabular}

The purpose of the second null hypothesis was to ascertain the difference between the number of types of dysgraphia errors observed in students speaking the Bulgarian verbal language (monolinguals) and students (Romas and Turks) using other linguistic codes in communication and the Bulgarian language.

Table 2: One-way analysis of variance for the relationship between ASDE errors and ethnicity

\begin{tabular}{|l|r|c|c|c|c|}
\hline $\begin{array}{l}\text { Source of } \\
\text { Variation }\end{array}$ & SS & df & MS & F & F crit \\
\hline $\begin{array}{l}\text { Between } \\
\text { Groups }\end{array}$ & 25696 & 7 & 3670.857 & 2.657197 & 1.549975 \\
\hline $\begin{array}{l}\text { Within } \\
\text { Groups }\end{array}$ & 37893.33 & 16 & 2368.333 & & \\
\hline & & & & & \\
\hline Total & 63589.33 & 23 & & & \\
\hline
\end{tabular}

Source: Authors

Analysis of the presented results showed that the participants bilinguals performed significantly worse on linguistic task than the monolingual control students $(\mathrm{F}=2.088929, \mathrm{~F}$ crit=1.234529). It can be explained by the fact that the written language is significantly much more abstract than the oral language. The written versions of the narrative contain syntactic complexity. The bilinguals are at risk for writing impairment due to their poor comprehension and metalinguistic skills and specific linguistic processing. They often struggle with the planning, organization, and revision needed to write, and frequently devote a disproportionate amount of cognitive energy to mechanics such as spelling, handwriting, punctuation. These results give support to Bishop and Clarkson (2003) views that writing is non-spontaneous and postulates greater explications, greater elaboration, greater formality. The written retelling requires skills for analysis and synthesis of linguistic and graphic constructions, transformation of linguistic and speech components into graphic patterns, an increased attention. The limit of these skills is the basis of the dominant amount of analytical-synthetic errors $(\mathrm{F}=2.657197, \mathrm{~F}$ crit=1.549975). The registered results (Table 2) reflected a statistically significant difference, as a result of which the second null hypothesis was rejected and $\mathrm{H}_{1}$ was accepted.

The third null hypothesis aimed to determine the difference between the total number of types of dysgraphia errors recorded in the boys and in the girls participating in the experiment. After the applied one-factor analysis of variance, it was found that between the boys and girls of the Bulgarian general education school there are statistically significant differences in the number of dysgraphia errors, which is proven by the values of the check value $\mathrm{F}(\mathrm{F}=5.323297, \mathrm{~F}$ crit=2.424364). As a result, this null hypothesis was rejected and the alternative $\mathrm{H}_{1}$ accepted.

\begin{tabular}{|c|c|c|c|c|c|c|}
\hline & $\begin{array}{l}\text { Source of } \\
\text { Variation }\end{array}$ & 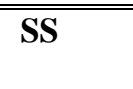 & df & MS & $\mathbf{F}$ & F crit \\
\hline & $\begin{array}{l}\text { Between } \\
\text { Groups }\end{array}$ & 38544 & 7 & 5506.286 & 26.37742 & 3.500464 \\
\hline & $\begin{array}{l}\text { Within } \\
\text { Groups } \\
\end{array}$ & 1670 & 8 & 208.75 & & \\
\hline & Total & 40214 & 15 & & & \\
\hline
\end{tabular}


This difference is most pronounced in ASDE errors (Table 3), given the values of $F((F=26.3774166$, $\mathrm{F}$ crit=3.500464), which are a major indicator of the impact of linguistic interference on males.

The fourth null hypothesis had to establish the difference between the total number of types of dysgraphia errors registered in the students living in different demographic areas: big city, small town, village. It was proven that the type of settlement is also a statistically significant factor for the relative share of dysgraphic errors $(\mathrm{F}=2.570829, \mathrm{~F}$ crit $=2.088929)$. The smallest number of errors was registered in the students from the big cities (623). The number of errors made by students in the small town (1373) and students living in rural municipalities (1459) is more than twice as high.

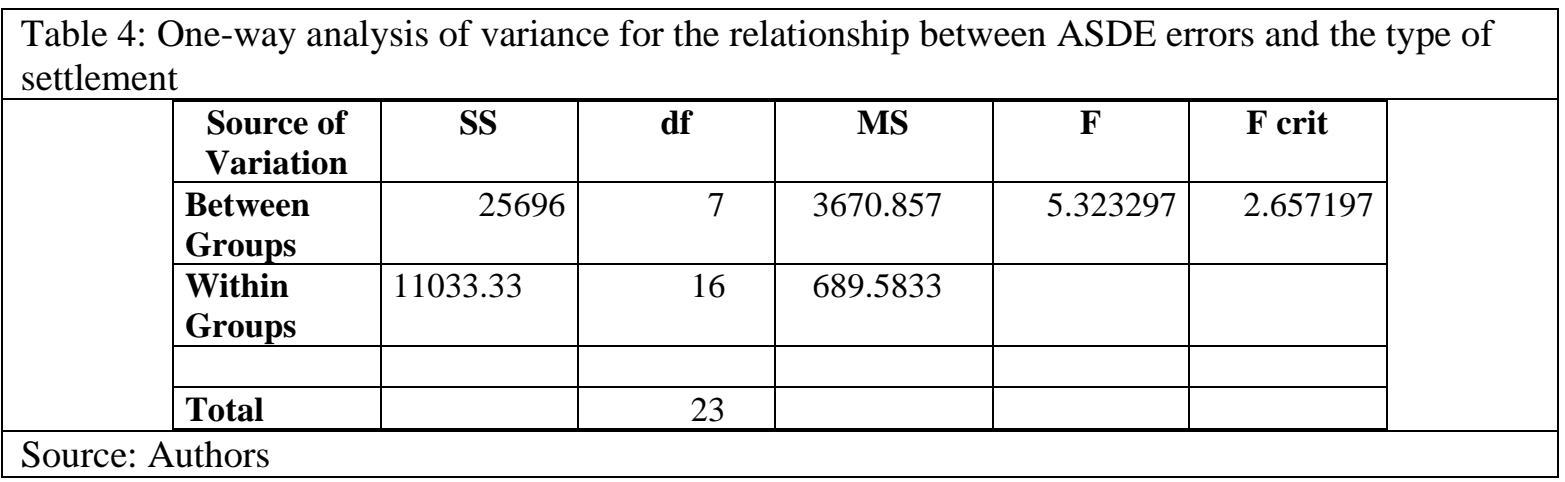

The dominant position of significance (Table 4) again belongs to the analytical-synthetic errors ( $\mathrm{F}=$ 5.323297367, F crit=2.657197), which are abundant in students living in small areas. Consequently, this null hypothesis was also rejected and the alternative $\mathrm{H}_{1}$ accepted. Of course, differences that are not statistically significant (VSCPL and WL) should not be underestimated - they can be a sign of certain trends and are also indicative.

\section{Discussion}

The present study examined the typology of dysgraphia errors in producing of written text by bilingual primary-school students. Written retelling is a complex task to accomplish in a linguistic and generally cognitive aspect. It is extremely indicative of the level of mastery of a language and its graphical system. The students had to retell a text read by the researcher based on the fairy tale genre. The writing activity was given as a seatwork in the classroom. A large number of errors were made in the implementation of the writing sample by the students in both groups. Fourteen types of errors, distributed in three groups, were found in the text written by Bulgarian (monolinguals), Turkish and Roma (bilingual) students. The analytical-synthetic errors prevailed over spelling errors and the errors, related to violation of the coordinate-spacing of letters. At the same time, although the monolinguals tend to fare better on literacy measures at school age when compared to students with bilingualism, they still struggle with correct use of written codes and spelling, most likely due to some phonological deficits. The latter, however, are strongly expressed in bilinguals.

The information gained from the written materials of students, as well as related literature revealed that the major source of the most errors is the interlingual interference. This is because the students always thought in their first language when they produced written Bulgarian language elements. The difference in language patterns is a big trouble for bilinguals. Interlingual interference is also the main cause of errors found in other researches (Kaweera, 2013). Intralingual interference is another crucial source of the bilinguals' errors. It is expressed in the students' confusion of using the target language. Their knowledge of the target language is incomplete, so they combined the knowledge of Turkish and Roma with that of Bulgarian. Very limited knowledge of Bulgarian grammar and vocabulary leads the students to commit errors. The data from the study confirm the need to improve language skills at the lexical and grammatical level.

Apart from the different phonetic systems and the linguistic interference that has proven to be a fundamental factor determining the dominant number of dysgraphia errors in the students from the Turkish and Roma ethnic communities, their presentation is largely related to the social context. Some authors even remarked that social factors are more important cause of the low level of bilingualism than linguistic factors (Jones, 2004). This study identified some factors that affected the performance of textbased writing in both groups of students - monolinguals and bilinguals. 
One of the most important factors was ethnicity. It is directly related to bilingualism and manifests itself as ethno-cultural features of the studied groups of individuals. While the Bulgarian students have done much better in performing the linguistic task, the same cannot be said of their Turkish and Roma peers. The sociocultural status of the Turkish and Roma language community affects the linguistic environment and the input bilinguals receive. The main reasons for the strong influence of the factor are the presence of a high degree of segregation and the lack or insufficient linguistic contacts in the integrating phonetic system, poor verbal communication outside their own ethnic group. As Moll (1992) states that for such students, the only input is teachers or classmates. The students are exposed to the second language only in the classroom where they spend less time in contact with the language covering a smaller discourse type. The limited exposure to the target language and lack of opportunities to practice speaking do not let their communicative abilities of L2 fully develop. The social distance between interlocutors can have a considerable influence on second language proficiency. Obviously, the specificity of the value system of the respective ethnic group, which does not meet the goals for higher education, is demotivating and neglecting.

The other no less important factor was gender. The study revealed the fact that the boys tend to have a much worse score in comprehension and written coding then the girls, and this difficulty may be exacerbated somewhat with development. The results of this study are consistent with the results of other studies which found that the gender is also associated with writing difficulties (Kingdon, Serbin and Stack, 2017). Yoshimasu and college (Yoshimasu et al. 2010) also prove a higher prevalence of spelling difficulties in boys as compared to girls, though Moll \& Landerl (2009) did not find a gender difference in writing difficulties. It is worth noting that different cultures sometimes define learning difficulties differently, and ways of identification writing difficulties can affect gender prevalence. Yet in most studies there tend to be more boys then girls. The results obtained, regarding the lower success of the boys in the written task, confirm the opinion in the research literature that girls develop linguistically better and at a faster pace than boys. The main reason is the biological differences between the genders, the slower maturation of the central nervous system in boys compared to girls, which is also manifested in the period of literacy. Some characteristic features of the genders probably have an additional influence - the female is generally more diligent in performing school tasks.

The type of settlement has also a statistically significant influence on the performance of the linguistic task. The results confirmed twice as many errors among the participants living in the small regions of the country. In small settlements and especially in villages, students (mostly Roma) are often absent from school, which generates a negative effect on the process of mastering graphic communication. The delays and unjustified absences of students from classes can be considered as an indicator of a specific attitude of their families to regular school attendance, which directly affects educational outcomes and leads to erosion of long-term motivation. In support of the above findings are data from specific studies (Jones, 2004). In addition, the present study inspires the idea that the settlement is an expression of the inevitable influence of the characteristic patterns of thought and behavior for a particular local community.

\section{Conclusion}

The results of the empirical study show that the linguistic situation in which the children of bilinguals are raised and educated is crucial for the degree of mastery of the Bulgarian language as a second (nonnative) language. The main reason is the influence of language interference in children who are mastering more than one language systems in their communication. Its effect on second language learning reflects on the mental attitudes and motivation of the bilingual child in the learning process and on its socialization and integration in general. The high requirements of the general education school call for more attention from the specialists (speech therapists, pedagogues) and 'a unique pedagogical style' (Shivacheva-Pineda, 2019; Teneva, 2018) in the teaching of the children to read and write, as well as to master the written communication. The results of the children who were covered in the survey revealed significant differences depending on gender, ethnicity and the type of settlement. The dominant number of errors was made by the boys of all groups, which is a significant predictor of dysgraphic identification. Significant differences in the typographic errors were found according to the type of settlement. The presence of a high degree of segregation and lack or insufficient language contacts in an integrative environment, the highly restricted verbal communication outside of the socioethnic/linguistic group, are among the leading determinants of the low levels of bilingualism. 
The linguistic development of bilingual children is relevant to theories of bilingual acquisition and to educational practices. It is hoped that somehow through this research, a contribution was done to the growing field of written discourse in bilingual students.

\section{References}

Abu-Rabia, S. \& Siegel, L. S. (2002). Reading, Syntactic, Orthographic, and Working Memory Skills of Bilingual ArabicEnglish Speaking Canadian Children, Journal of Psycholinguistics, 31 (6), 661-678.

Bishop, DVM, Clarkson, B. (2003). Written language as a window into residual language deficits: A study of children with persistent and residual speech and language impairments, Cortex, 39, 215-237.

Chen, X., Xu, F., Nguyen, T., Hong, G. \& Wang, Y. (2010). Effects of cross-language transfer on first-language phonological awareness and literacy skills in Chinese children receiving English instruction. Journal of Educational Psychology, 102, 712728 .

Cummins, J. (1976). The influence of bilingualism onward cognitive growth: A synthesis of research findings and explanatory hypotheses, Working Papers forward Bilingualism, 9, 1-43.

Figueredo, L. (2006). Using the known to chart the unknown: A review of first language influence on the development of English-as-a-second-language spelling skill. Reading and Writing, 19, 873-905.

Houghton, G., \& Zorzi, M. (2003). Normal and impaired spelling in a connectionist dual-route architecture. Cognitive Neuropsychology, 20, 115-162.

Jones, J. F. (2004) A cultural context for language anxiety, English Australia Journal, 21 (2), 30-39.

Kaweera, Ch. (2013). Writing error: A review of interlingual and intralingual interference in EFL context, English Language Teaching, 6 (7), 9-18.

Kingdon, D., Serbin, L., Stack, D. (2017). Understanding the gender gap in school performance among low-income children: A developmental trajectory analysis, International Journal of Behavioral Development, 41 (2), 265-274.

Koleva, Ir. (1994). Concept for socialization of Roma children in disadvantaged social status, S.

Kyuchukov, H. (2002). The written Bulgarian language of Roma pupils in 3th-5th grade, S.

Moll, L. (1992) Bilingual classroom studies and community analysis: Some recent trends, Educational Researcher 21 (2), 20 24.

Moll, K., \& Landerl, K. (2009). Double dissociation between reading and spelling deficits. Scientific Studies of Reading, 13, 359-382.

Rowse, H. J. \& Wilshire, C. E. (2007). Comparison of phonological and whole-word treatments for two contrasting cases of developmental dyslexia. Cognitive Neuropsychology, 24 (8), 817-842.

Sebastian, R., Laird, A. \& Kiran, S. (2011). Meta-analysis of the neural representation of firs language, Applied Psycholinguistics, 32, 799-819.

Simeonova, A. I. (2007). The Roma in Bulgaria: the new challenges, Report of Foundation "Friedrich Ebert".

Stamov, V. (1989). Speech therapy, B1.

Teneva, M. (2018). Professional characteristics and qualities of teacher, Pedagogy, 90 (2), 194-204.

Shivacheva-Pineda, I. (2019). Teacher's profesional-lersonal reflection, Pedagogy, 91 (5), 615-625.

Weekes, W. S. (2005). Acquired disorders of reading and writing: cross-script comparisons. Behavioural Neurology, 16 (2-3), 51-57.

Wei, L. (2002). The Bilingual Mental Lexicon and Speech Production Process. Brain and Language, 81, 691-707.

Yoshimasu, K., Barbaresi, W. J., Colligan, R. S., Killian, J. M., Voigt, R. G., Weaver, A. L. \& Katusic, S. K. (2010). Gender, attention-deficityperactivity disorder, and reading disability in a population-based birth cohort, Pediatrics, 126 (4) 788-795. 